\title{
Chapter 4 \\ Double Insurance in Dealing with Extremes: Ecological and Social Factors for Making Nature-Based Solutions Last
}

\author{
Erik Andersson, Sara Borgström, and Timon McPhearson
}

\begin{abstract}
Global urbanisation has led to extreme population densities often in areas prone to problems such as extreme heat, storm surges, coastal and surface flooding, droughts and fires. Although nature based solutions (NBS) often have specific targets, one of the overarching objectives with NBS design and implementation is to protect human livelihoods and well-being, not least by protecting real estate and built infrastructure. However, NBS need to be integrated and spatially and functionally matched with other land uses, which requires that their contribution to society is recognised. This chapter will present an ecologically grounded, resilience theory and social-ecological systems perspective on NBS, with a main focus on how functioning ecosystems contribute to the 'solutions'. We will outline some of the basic principles and frameworks for studying and including insurance value in work towards climate change adaptation and resilience, with a special emphasis on the need to address both internal and external insurance. As we will demonstrate through real world examples as well as theory, NBS should be treated as dynamic components nested within larger systems and influenced by social as well as ecological factors. Governance processes seeking to build urban resilience to climate change in cities and other urban dynamics will need to consider both layers of insurance in order to utilize the powerful role NBS can play in creating sustainable, healthy, and liveable urban systems.
\end{abstract}

E. Andersson $(\bowtie)$

Stockholm Resilience Centre, Stockholm University, Stockholm, Sweden e-mail: erik.andersson@su.se

S. Borgström

School of Architecture and the Built Environment, KTH Royal Institute of Technology,

Stockholm, Sweden

e-mail: sara.borgstrom@abe.kth.se

T. McPhearson

Urban Ecology Lab, Environmental Studies, The New School, New York, NY, USA

e-mail: timon.mcphearson@ @ewschool.edu 
Keywords Extreme weather events $\bullet$ Infrastructure $\bullet$ Resilience $\bullet$ Insurance value $\bullet$ Social-ecological systems $\bullet$ Vulnerability $\bullet$ Social acceptance $\bullet$ Multifunctionality $\bullet$ Flexibility $\bullet$ Participation

\subsection{Introduction}

Societies have suffered from extreme weather events throughout human history, and despite tremendous technological advances over the last centuries we are today - in some ways - even more vulnerable than before. Global urbanisation has led to extreme population densities often in areas prone to problems such as extreme heat, storm surges, coastal and surface flooding, droughts and fires (Grimm et al. 2000). We are also increasingly dependent on infrastructure for our daily lives - transportation of different kinds, communication networks, and power supply chains to mention just a few. The reduction of risk, not least in the context of a changing climate and the prospect of more frequent weather extremes (Coumou and Rahmstorf 2012), is a primary target for nature based solutions (NBS). Although NBS often have specific targets, one of the overarching objectives with NBS design and implementation is to protect human livelihoods and well-being, not least by protecting real estate and built infrastructure, and unless otherwise specified this is what we mean by 'protection' in this chapter. To do this, we argue that NBS need to be integrated and spatially and functionally matched with other land uses, which requires that their contribution to society is recognised.

This chapter will present an ecologically grounded, resilience theory and socialecological systems perspective (Box 4.1) on NBS with a main focus on how functioning ecosystems contribute to NBS, rather than green technology or hybrid systems with often a more minor biological component. We argue that the implications of such a perspective are critical for how we think about and design NBS as a long term strategy to deal with climate change and, especially, its effects in terms of extreme events. As we will show, NBS need to meet two criteria to provide longterm protection: First, they must fit functionally and spatially with the vulnerable areas (e.g. by providing a barrier between the source of a disturbance and potential sufferers) and be sufficiently sized to match the magnitude of the disturbance. Second, the NBS themselves need be resilient to the disturbance and long lag times between events; they must be perceived as valuable, and thus supported, in times when this capacity is not actively in use. This is especially true in densely populated and contested urban landscapes, where other land uses constantly challenge the preservation and protection of functioning ecosystems (Depietri and McPhearson 2017, Chap. 6, this volume).

We will outline some of the basic principles and frameworks for studying and including insurance value (Box 4.2) in work towards climate change adaptation and resilience. As we will demonstrate through real world examples as well as theory, NBS should be treated as dynamic components nested within larger systems and influenced by social as well as ecological factors. Since cities and urbanizing regions are both very vulnerable to weather extremes and other climate change effects, and 


\section{Box 4.1 Resilience in Social-Ecological Systems}

Resilience, as we here use it, has its roots in a seminal paper published by Holling in 1973 (Holling 1973), where he proposed that ecosystem dynamics are non-linear and that there are certain properties that make it more likely that a system retain its functions and character despite disturbances and changing drivers. A resilient system would thus be one that can absorb shocks, and reorganise, without undergoing fundamental change. As this chapter describes, the first writing on resilience within this school of thought had a strong ecological focus. Later, resilience thinking became a dominant approach within studies of social-ecological systems, adding to the study of the ecological properties of different ecosystems and species assemblages the different connections and interactions between people and the nature they are part of (Berkes and Folke 1998). Following this line, later iterations of resilience have included more social factors and now also explicitly include transformations within a development process as one of the necessary ingredients in a resilient system (Folke 2006). In accordance, we argue that NBS and their resilience are made up of social-ecological components and interactions, making governance a key challenge for resilience building. Further, transformation, in the context of this chapter, means that the embedding system around the NBS may need to shift and change, sometimes profoundly, to make sure that the NBS and the insurance they offer survive fundamental changes like an altered climate and new weather regimes.

\section{Box 4.2 Insurance Value}

The societal importance of ecosystems and biodiversity in buffering shocks, climate change induced weather extremes prominently among them, is increasingly examined through the metaphor of insurance value (Baumgärtner 2007; Green et al. 2016). Referring to the insurance value offered by ecosystems suggests that there is a critically important value in the structure and core ecosystem processes responsible for maintaining ecosystem functions and properties (e.g. Perrings 1995; Millennium Ecosystem Assessment 2005). Recognising that multiple definitions exist, we use insurance value to reflect the avoided socioeconomic and wellbeing costs associated with weather related disasters, and insurance itself as the maintenance of ecosystem services provided by social-ecological systems despite variability, disturbance and management uncertainty. With this definition, the insurance value of an ecosystem is closely related to its resilience, self-organizing capacity, and to what extent it may continue to provide flows of ecosystem service benefits over a range of variable environmental conditions (Green et al. 2016). While these aspects are increasingly appreciated in the work on NBS and insurance against climate change, we argue that the field has yet to recognise the need for making the NBS themselves survive over time. 
tend not to give full consideration to functioning ecosystems as critical components of climate change adaptation, we focus on examples from such systems. That said, this approach should still be applicable to most or all social-ecological systems. Applying a 'double insurance' thinking, external and internal, can be seen as one step towards governance processes that better take into account the complexity of the systems we live in and the multifaceted nature of urban pressures and disturbances.

\subsection{External Insurance}

\subsubsection{Ecological Foundations}

Ecosystems of different kinds have been shown capable of mitigating weather extremes and thereby protecting other parts of urban systems and reducing the impact of disturbances (McPhearson et al. forthcoming). Examples include coastal ecosystems that provide a physical barrier from storm surges (Costanza et al. 2006; Koch et al. 2009), open land and permeable surfaces that protect from flooding through percolation (Farrugia et al. 2013) and urban trees and forests that mitigate heat waves (Jenerette et al. 2011; Depietri et al. 2012). Ecosystems differ from the more inert physical elements of many 'conventional' solutions. While, for example, coastal wetlands may provide coastal protection from storm surge and flooding, similar to sea walls, the wetlands do this as an integral part of an internal dynamics of wetland ecosystems. All ecosystems have their own dynamics, and to understand when, why and where they help us deal with climate change and its consequences requires knowledge of the fundamentals of systems ecology. It is important to get down to the details of understanding the role for species, species interactions, spatial structure, and how these together generate (or not) the ecological contribution to NBS insurance. Ecological character also has bearing on the efficiency of the NBS, and will influence how they compare to alternative solutions (cf. The Royal Society 2014).

Ecosystem function and resilience is an outcome of the organisms present in the system and their interactions - with each other and the physical environment (e.g. Chapin et al. 1997). The life history traits of an organism, such as physiology, behaviour, resource use and competitive strategies, determine both the ecological functions it contributes to and how it may respond to different disturbances and pressures (e.g. Mori et al. 2013). These traits comprise characters that affect soil stabilisation, water retention, radiation reflectance and different shielding effects (waves, noise, high winds etc.), among other things. In and of themselves, or in different combinations, these characters are the foundation for the first type of insurance value offered by NBS. For example, the shading and evapotranspiration by urban forest trees, which provide important cooling benefits in increasingly hot urban areas, depend on ecological processes like nutrient retention and cycling traits of soil microbes and invertebrates to maintain health and function of urban trees (Ballinas and Barradas 2016). Similarly, vegetation growing along urban riparian 
areas directly affect the outflow of water via the reduction of surface flow velocity, the partitioning of precipitation via canopy interception, evaporation and the promotion of infiltration, and via water uptake, storage and transpiration (Brauman et al. 2007; Nepf 2012; Gurnell 2014). Plants can also provide soil stabilization, which allows soil organism communities to develop. Riparian soils then are able provide important ecosystem functions such as nitrogen retention important in areas with significant upstream nitrogen fluxes (Groffman et al. 2003, 2004) and thus reduce the risk of soil erosion and eutrophication.

\subsubsection{Vulnerability and Exposure}

There is still considerable need for fundamental research on the ecological characteristics that could mitigate the effects of extreme events and climate change. Sound ecological knowledge is the first building block for understanding how to design NBS to meet different needs. These needs can be understood as the 'demand' for protection, and are very much determined by socioeconomic factors and cannot be captured by a biophysical assessment alone. An ecologically suitable NBS will only deliver expected solutions if it is sufficiently sized and adequately located (cf. Andersson et al. 2015). The answers to both these questions need to be sought in the larger social-ecological system - as is clearly demonstrated by the literature on vulnerability and exposure (e.g. Adger et al. 2005; Folke 2006).

According to IPCC "vulnerability describes a set of conditions of people that derive from the historical and prevailing cultural, social, environmental, political, and economic contexts" and "the propensity of exposed elements such as human beings, their livelihoods, and assets to suffer adverse effects when impacted by hazard events" (IPCC 2012, p. 71 and p. 69, respectively), while exposure refers to an "inventory of elements in an area in which hazard events may occur" (ibid., p. 69). While the literature and common usage sometimes conflate the two they do capture different aspects. To be vulnerable you must be exposed to the risk, but exposure alone is not sufficient. Awareness of exposure together with appropriately planned and implemented adaptation measures may at least reduce the vulnerability of people and property.

If NBS are to contribute to making communities less vulnerable they must be sized to match the magnitude of the disturbance and the extent of the exposed area. For example, bioswales and other types of green infrastructure being employed around the world in cities to provide NBS for mitigating surface flooding may fail if overwhelmed by large or extreme precipitation or flood events. Second, they need to be located in the right place. There are several possible spatial relationships between the source of the insurance capacity - the NBS - and where people and property may benefit from it (see e.g. Fisher et al. 2009; Renaud et al. 2016). Most usually, the insurance is achieved by the NBS providing a 'buffer' between the exposed area and the potential risk, e.g. wetlands upstream or along the coast outside a city (see Haase 2017, Chap. 7, this volume). This connection between the NBS and their beneficiaries is mediated by social structures such as built infrastructure 
and institutions defining access to land and designating land uses as well as socioeconomic priorities of management and stewardship.

\subsection{Internal Insurance}

\subsubsection{The Role of Diverse Ecosystems}

Of concern in cities facing significant climate challenges is that assumed protection through NBS may fail when the ecosystems themselves are not adequately resistant and resilience to climate and other disturbances (McPhearson et al. 2015). Fundamental for the second level of insurance - the survival of the NBS themselves - is how the NBS respond to different pressures. This can be ecologically captured by the robustness, the capacity to cope and continue to deliver the desired function during an event, and by the presence of alternative functional pathways (e.g. different types of vegetation providing shading or soil stabilisation) with differential ability to respond to and cope with different pressures over time. Elmqvist and co-authors (2003) pointed to the importance of response diversity for being able to deal with changes, which in the context of this chapter can be understood as NBS being built up by components (organisms or communities) with differences in their responses to disturbances. By making sure that the NBS that are expected to help us cope and adapt to climate change are robust and resilient enough to withstand not only weather extremes and climate change itself, but a spectrum of different disturbances, we increase the probability that they will persist over time and thus be there when the rare, extreme events occur (cf. Mori et al. 2013).

To provide an example, urban forests are being widely used as NBS and generally considered as important to mitigate several weather related hazards - they keep the temperature down during heat waves, they can stabilize soils and help in preventing flooding (Roy et al. 2012; Livesley et al. 2016). However, despite this wide recognition of value, the fact that urban forests themselves may be vulnerable to the same disturbances is less recognised. Most studies that have looked at the benefits of such forests are based upon the species, number and size of trees in the urban landscape and how these shape effect (Nowak et al. 2013; Farrugia et al. 2013; Livesley et al. 2016). Less attention has been dedicated to the benefits of diversity and species specific traits in the composition of the forests, and when discussed it is usually along broad theoretical reasons for why diversity is important (Muller and Bornstein 2010). While tree population diversity is regarded as desirable few studies directly reflect or inform on the capacity of different tree species and species assemblages to deal with environmental stresses (May et al. 2013). For example, while temperature regulation - especially mitigating extreme heat - is one of the most important services trees can contribute, trees are also sensitive to drought, which is often associated with periods of above average temperatures and heat waves (Déry and Wood 2005). Drought induces physiological stress that may either kill the tree or make it vulnerable to pest attacks or disease challenges or fully inhibiting the 
ability of trees to provide the functions needed for NBS to heat (McDowell et al. 2011).

\subsubsection{Spatial Dynamics}

Beyond life history traits, spatial dynamics have been highlighted as an essential factor for resilience (Webb and Bodin 2008; Allen et al. 2016). In principle, having connections between for example the specimens of a specific type of NBS will usually promote the resilience of the individual NBS as well as the connected network of NBS. Each node in the network can potentially support the other nodes by replenishing locally extirpated populations and facilitating reorganisation (e.g. Hanski and Gilpin 1991; Bengtsson et al. 2003). While perhaps more indirect than the immediate response to disturbance, these processes make it more likely that the NBS survives and are in place to support system resilience when needed. However, connectivity can be problematic as some of the disturbances that challenge NBS may follow the same linkages (Holling et al. 2002; Allen et al. 2014).

For this reason, modularity has been suggested as a fluid middle way where smaller groups of nodes within a network are internally well connected but relatively isolated from other groups (e.g. Webb and Bodin 2008). Bioswales are a good example for how modularity can help maintain resilience. Since they are often small and spatially disaggregated, failure of one set of bioswales may not impact bioswales in other locations in the city allowing continued functioning for flood mitigation in places where bioswales did not fail. Similarly, street trees, which tend to be spatially separated, may be able to sustainably provide NBS when faced with disturbances more reliably in some instances than more spatially aggregated trees in urban forests. Tree insect pests, which may become increasingly threatening to NBS (Dale and Frank 2014), can spread more easily among closely growing tree stands. Here again, the principle of modularity where redundant functions are disaggregated can help to ensure continued green infrastructure performance for mitigating effects of climate change in cities.

\subsubsection{Public Support: Making Sense of NBS}

Ecological factors and features are, however, only one side of making NBS themselves resilient. NBS are embedded in social-ecological systems and social aspects are critical, for example political and economic priorities, human perceptions, norms and values, historical legacies and institutional contexts. Besides promoting governance that supports the necessary ecological underpinnings of NBS, a double insurance thinking approach to NBS also requires flexibility and open-ended designs to handle shifting priorities, and form strategies for long-term public support.

The survival of a NBS over time, especially in systems with a very active presence of people, depends on how people view them, and how they are managed. If 
the function of a NBS is not appreciated or understood, it risks being replaced by something else with a more apparent value to people. Climate change may make weather extremes more frequent, but there is still quiet periods between the times when NBS are needed and when their function and value are less evident (cf. Andersson et al. 2015). Also, diversity in preferences must be taken into account; an NBS might be attractive to some while disagreeable to others. One example is dense forests, which are of great recreational values to some people while perceived as unsafe and dangerous by others. Wetlands is another; they can be seen as either beautiful, rich bird habitats providing flood protection and water cleaning, or as breeding grounds for parasites caring diseases and environments that create risks for drowning accidents.

One way of engaging with social acceptance is to make sure that the NBS are multi-functional and, most importantly, that they have clear functions also during the periods between extreme events. Multi-functional green structures are today increasingly discussed and also implemented as a solution to the decreasing extent of green space in densifying cities (e.g. Gomez-Baggethun et al. 2013). However, presently this is mostly a matter of designing green structures to meet multiple demands at the same location at the same time, less about safeguarding multiple latent functions that can be activated or utilized when needed. The availability of different functions, and sometimes the magnitude of their effect, is also a question of the institutional set up, where different user rights and policy recommendations can shift and intentionally or unintentionally change functionality by emphasizing, strengthening or suppressing different functions. An example of this is the current trend of urban gardening, which while in many ways adding functionality to many urban green spaces might suppress other functions or the access to these.

In addition to direct utility, ecological quality, and long term resilience, must be better recognised and appreciated if we are to reach a publically supported double insurance. With increasingly participatory approaches to NBS design and management, finding ways to incorporate functions that are not needed at present and that are for a common good (flood prevention) instead of specific interests (urban gardening) is an urgent and challenging necessity.

\subsection{Investing in Insurance: Governance Frameworks}

How can we design and plan for NBS that provide protection to present large scale disturbances and at the same time also can withstand drastic economic and social fluxes at different scales (e.g. the recent European economic and migration crises) without losing their long-term functionality and protective capacity? The effectiveness of each NBS element is dependent on the interactions with the surroundings as well as remotely connected complex systems. This reinforces the need for governance approaches to shift focus to anticipating, planning for, and navigating change instead of planning for a presumed controlled development driven by a few, often disconnected social and economic parameters (Duit et al. 2010). This calls for 
increasing connections between levels of governance and across professions, where for example green spaces are not treated as an isolated entity but integrated functional entities in the urban fabric.

\subsubsection{Flexibility}

An ecologically resilient NBS also needs a resilient governance system which implies a shift towards more adaptive and participatory approaches (Biggs et al. 2015). The need to explore new ways of NBS planning (spatially and practically), knowledge development and transfer, and NBS design and maintenance - all with a long time perspective, is at odds with current often short term, mainstreamed and efficiency driven NBS governance. A more adaptive mode of NBS governance means embracing experimental approaches, where evaluation of goals, measures and outcomes are built into continuous learning (Walters 1986). It also requires a high degree of flexibility and open-endedness where present requirements for functionality and protection are constantly weighed against the long-term capacity of the NBS to respond to yet unknown disturbances and changing demands and needs. This requires political and public acceptance of failures as learning leverages in NBS planning, design and management. One important aspect is to identify and articulate how to sustain options for the future, making sure that an NBS with certain function can also be used to provide other services if needed. For example, an urban green space that is today mostly used for outdoor recreation, but in times of heavy rain can act as a reservoir for water and thereby protect surrounding areas for getting flooded. Another spin to multifunctionality and flexibility is our tendency to build identity and value on continuity (with its fallacy for command and control (Holling and Meffe 1996)). Although challenging, a shift to increased temporal variation in what functions of an NBS are promoted could support resilience in two ways: it would make change rather than permanence part of people's everyday life (and perhaps something that could be of value in itself), and it would encourage more nimble governance where land designations, procedures, policy and institutional framings are less static. Here more research is needed.

\subsubsection{Participation}

The need for participation in resilient NBS governance goes far beyond public hearings in the planning phase. Reflecting and similar to the ecological principles, diversity in the social components of social-ecological systems is perhaps the most important characteristic. An NBS that is planned and designed in a way that makes it heavily dependent on one actor's flow of resources, organisation, institutional framework and motivation, is very vulnerable to social and economic changes relating to that particular actor. This is evident in several cities in Europe where the public 
finances have been severely impacted by economic crisis lately and the character of many green spaces has changed, either into vacant lots or into management by volunteering local groups. In heavily human influenced ecosystems new management regimes often lead to an altered functionality (cf. Andersson et al. 2007). This illustrates that functionality and mainstreaming of NBS are closely connected to multiactor engagement and partnerships that provide a greater diversity of knowledges and practices, ranging from expert to experience driven, from which the experimental approach can draw (Tengö et al. 2014). In order to recognise the system context of the NBS it is necessary to create governance linkages that match these interactions and dependencies (Andersson et al. 2014). The participatory component of resilient governance is also a matter of creating economic insurance, where different financial resources can be activated to sustain functionality over time. Furthermore, it is about relying on multiple actors for continuous knowledge generation, e.g. citizen science (Krasny et al. 2014), knowledge transfer over time (Andersson and Barthel 2016) and practical management. This will in turn be of importance for the social support of the NBS existence and awareness of its changing functional design over time.

\subsection{Conclusions}

Ecosystems and green and blue infrastructure can provide long-term insurance to climate change, making them an integral part of strategies to meet this multi-faceted challenge (Table 4.1). However, the extent to which they will be able to do this will depend both on their quality and the context they are set in. First, the ability of NBS to provide insurance against impacts of extreme events requires understanding of

Table 4.1 The two levels of insurance. Definitions, key factors underlying the insurance capacity and key aspects of governance that could promote and support them

\begin{tabular}{l|l|l|l}
\hline & Definition & Key factors & Governance \\
\hline $\begin{array}{l}\text { 1st level of } \\
\text { external }\end{array}$ & $\begin{array}{l}\text { Capacity to } \\
\text { protect the larger } \\
\text { system based on } \\
\text { regulating } \\
\text { ecosystem } \\
\text { functions and } \\
\text { location relative } \\
\text { to vulnerable } \\
\text { areas }\end{array}$ & $\begin{array}{l}\text { Ecosystem configuration, } \\
\text { spatial location, the nature } \\
\text { of exposure }\end{array}$ & $\begin{array}{l}\text { Spatial planning, value } \\
\text { recognition, cross boundary } \\
\text { considerations and linkages }\end{array}$ \\
\hline $\begin{array}{l}\text { 2nd level of } \\
\text { insurance, }\end{array}$ & $\begin{array}{l}\text { Robustness } \\
\text { during an event } \\
\text { and resilience } \\
\text { over time, the } \\
\text { survival of the } \\
\text { NBS itself }\end{array}$ & $\begin{array}{l}\text { Response diversity, } \\
\text { multifunctionality, } \\
\text { participation and } \\
\text { involvement, broad } \\
\text { recognition of value }\end{array}$ & $\begin{array}{l}\text { Participative processes, } \\
\text { recognition of multiple } \\
\text { values, legal frameworks and } \\
\text { recommendations that can } \\
\text { facilitate flexible use over } \\
\text { time }\end{array}$ \\
\hline
\end{tabular}


spatial context of ecosystems. If an NBS is not properly positioned, it will do little to mitigate extreme events. Coastal cities need coastal wetlands physically located between them and a storm surge if wetlands are to provide resilience to coastal storms. This first insurance value stems from NBS being entities with physical attributes, but, of course, they are more than that. They are alive, and often constitute complex systems in themselves. Functioning ecosystems interact with the larger social-ecological systems they are embedded in and have their own vulnerabilities and resilience. The second layer of insurance, the survival of the NBS over time, has both ecological and social roots. Ecologically, this can be described and assessed through the functional traits present in an NBS and through its functional linkages to its surroundings, e.g. as part of a blue or green network. Following from these, key principles for building resilience are to promote diversity among response traits and to find an appropriate level of modularity.

On the social side, we have highlighted flexibility in the governance of NBS and recognition and support from the public. NBS governance includes promoting diversity and redundancy, and having more open-ended and adaptive decision-making processes for governing ecosystems for multi-functionality in the face of multiple changes and pressures. Additionally, public support for specific and often mostly dormant NBS (the need for insurance is not constant but linked to occasional events (Andersson et al. 2015)) can be strengthened by managing and planing them to be multifunctional over time, and by making sure that some functions achieve social purposes even in the periods between extreme events. Governance processes seeking to build urban resilience to climate change and other urban dynamics will need to consider both layers of insurance in order to utilize the powerful role NBS can play in creating sustainable, healthy, and liveable urban systems. Though NBS are complex, which this chapter's discussion on a number of less considered aspects of social-ecological complexity of NBS has demonstrated, working with NBS remains an unrealized and high potential opportunity for resilience building that fits well within the power and capacity of planning offices or stewardship bodies to achieve.

\section{References}

Adger WN, Arnell NW, Tompkins EL (2005) Successful adaptation to climate change across scales. Glob Environ Chang Part A 15:77-86

Allen CR, Angeler DG, Garmestani AS et al (2014) Panarchy: theory and application. Ecosystems. doi:10.1007/s10021-013-9744-2

Allen CR, Angeler DG, Cumming GS et al (2016) REVIEW: Quantifying spatial resilience. J Appl Ecol 53:625-635. doi:10.1111/1365-2664.12634

Andersson E, Barthel S (2016) Memory carriers and stewardship of metropolitan landscapes. Ecol Indic 70:606-614. doi:10.1016/j.ecolind.2016.02.030

Andersson E, Barthel S, Ahrné K (2007) Measuring social-ecological dynamics behind the generation of ecosystem services. Ecol Appl 17:1267-1278. doi:10.1890/06-1116.1

Andersson E, Barthel S, Borgström S et al (2014) Reconnecting cities to the biosphere: stewardship of green infrastructure and urban ecosystem services. Ambio 43:445-453. doi:10.1007/ s13280-014-0506-y 
Andersson E, McPhearson T, Kremer P et al (2015) Scale and context dependence of ecosystem service providing units. Ecosyst Serv 12:157-164. doi:10.1016/j.ecoser.2014.08.001

Ballinas M, Barradas VL (2016) The urban tree as a tool to mitigate the urban heat island in Mexico City: a simple phenomenological model. J Environ Qual 45:157-166. doi:10.2134/ jeq2015.01.0056

Baumgärtner S (2007) The insurance value of biodiversity in the provision of ecosystem services. Nat Resour Model 20:87-127. doi:10.1111/j.1939-7445.2007.tb00202.x

Berkes F, Folke C (eds) (1998) Linking social and ecological systems: management practices and social mechanisms for building resilience. Cambridge University Press, Cambridge.

Bengtsson J, Angelstam P, Elmqvist T et al (2003) Reserves, resilience and dynamic landscapes. Ambio 32:389-396

Biggs R, Schlûter M, Schoon ML (eds) (2015) Principles for building resilience: sustaining ecosystem services in social-ecological systems. Cambridge University Press, Cambridge

Brauman KA, Daily GC, Duarte TK, Mooney HA (2007) The nature and value of ecosystem services: an overview highlighting hydrologic services. Annu Rev Environ Resour 32:67-98. doi:10.1146/annurev.energy.32.031306.102758

Chapin FS, Walker BH, Hobbs RJ, et al (1997) Biotic control over the functioning of ecosystems. Science (80- ) 277:500-504

Costanza R, Mitsch WJ, Day JW Jr (2006) A new vision for New Orleans and the Mississippi delta: applying ecological economics and ecological engineering. Front Ecol Environ 4:465-472

Coumou D, Rahmstorf S (2012) A decade of weather extremes. Nat Clim Chang 2:491-496. doi:10.1038/nclimate 1452

Dale AG, Frank SD (2014) The effects of urban warming on herbivore abundance and street tree condition. PLoS One 9:e102996. doi:10.1371/journal.pone.0102996

Depietri Y, Renaud FG, Kallis G (2012) Heat waves and floods in urban areas: a policy-oriented review of ecosystem services. Sustain Sci 7:95-107. doi:10.1007/s11625-011-0142-4

Déry SJ, Wood EF (2005) Observed twentieth century land surface air temperature and precipitation covariability. Geophys Res Lett 32:L21414. doi:10.1029/2005GL024234

Duit A, Galaz V, Eckerberg K, Ebbesson J (2010) Governance, complexity, and resilience. Glob Environ Chang 20:363-368. doi:10.1016/j.gloenvcha.2010.04.006

Elmqvist T, Folke C, Nyström M et al (2003) Response diversity, ecosystem change, and resilience. Front Ecol Environ 1:488-494

Farrugia S, Hudson MD, McCulloch L (2013) An evaluation of flood control and urban cooling ecosystem services delivered by urban green infrastructure. Int J Biodivers Sci Ecosyst Serv Manag 9:136-145. doi:10.1080/21513732.2013.782342

Fisher B, Turner RK, Morling P (2009) Defining and classifying ecosystem services for decision making. Ecol Econ 68:643-653. doi:10.1016/j.ecolecon.2008.09.014

Folke C (2006) Resilience: the emergence of a perspective for social-ecological systems analyses. Glob Environ Chang 16:253-267. doi:10.1016/j.gloenvcha.2006.04.002

Green TL, Kronenberg J, Andersson E, Elmqvist T, Gómez-Baggethun E (2016) Insurance value of green infrastructure in and around cities. Ecosystems 19:1051-1063. doi:10.1007/ s10021-016-9986-X

Gomez-Baggethun EP, Gren Å, Barton D et al (2013) Urban ecosystem services. In: Elmqvist T, Fragkias M, Goodness J et al (eds) Global urbanization, biodiversity, and ecosystems challenges and opportunities cities and biodiversity outlook - scientific analyses and assessments. Springer, Dordrecht, pp 175-251

Grimm NB, Grove JM, Pickett STA, Redman CL (2000) Integrated approaches to long-term studies of urban ecological systems. Bioscience 50:571-583

Groffman PM, Bain DJ, Band LE et al (2003) Down by the riverside: urban riparian ecology. Front Ecol Environ 1:315-321. doi:10.1890/1540-9295(2003)001[0315:DBTRUR]2.0.CO;2

Groffman PM, Law NL, Belt KT et al (2004) Nitrogen fluxes and retention in urban watershed ecosystems. Ecosystems. doi:10.1007/s10021-003-0039-x 
Gurnell A (2014) Plants as river system engineers. Earth Surf Process Landforms 39:4-25. doi:10.1002/esp.3397

Hanski I, Gilpin ME (1991) Metapopulation dynamics: empirical and theoretical investigations. Academic, London

Holling CS (1973) Resilience and stability of ecological systems. Annu Rev Ecol Syst 4:1-23.

Holling CS, Meffe GK (1996) Command and control and the pathology of natural resource management. Conserv Biol 10:328-337

Holling CS, Gunderson LH, Peterson GD (2002) Sustainability and panarchies. In: Gunderson LH, Holling CS (eds) Panarchy. Understanding transformations in human and natural systems. Island Press, Washington, DC, pp 63-102

IPCC (2012) Managing the risks of extreme events and disasters to advance climate change adaptation: special report of the intergovernmental panel on climate change. Cambridge University Press, Cambridge/New York

Jenerette GD, Harlan SL, Stefanov WL, Martin CA (2011) Ecosystem services and urban heat riskscape moderation: water, green spaces, and social inequality in Phoenix, USA. Ecol Appl 21:2637-2651. doi:10.1890/10-1493.1

Koch EW, Barbier EB, Silliman BR et al (2009) Non-linearity in ecosystem services: temporal and spatial variability in coastal protection. Front Ecol Environ 7:29-37. doi:10.1890/080126

Krasny ME, Russ A, Tidball KG, Elmqvist T (2014) Civic ecology practices: participatory approaches to generating and measuring ecosystem services in cities. Ecosyst Serv 7:177-186. doi:10.1016/j.ecoser.2013.11.002

Livesley SJ, McPherson GM, Calfapietra C (2016) The urban forest and ecosystem services: impacts on urban water, heat, and pollution cycles at the tree, street, and city scale. J Environ Qual 45:119-124. doi:10.2134/jeq2015.11.0567

May PB, Livesley SJ, Shears I (2013) Managing and monitoring tree health and soil water status during extreme drought in Melbourne, Victoria. Arboricult Urban For 39:136-145

McDowell NG, Beerling DJ, Breshears DD et al (2011) The interdependence of mechanisms underlying climate-driven vegetation mortality. Trends Ecol Evol 26:523-532. doi:10.1016/j. tree.2011.06.003

McPhearson T, Andersson E, Elmqvist T, Frantzeskaki N (2015) Resilience of and through urban ecosystem services. Ecosyst Serv 12:152-156. doi:10.1016/j.ecoser.2014.07.012

McPhearson T, Karki M, Herzog $\mathrm{C}$ et al forthcoming Urban ecosystems and biodiversity. In: Rozensweig C, Solecki B, AlE (eds) Urban Climate Change Research Network Second Assessment Report on Climate Change in Cities (ARC3-2). Cambridge University Press, Cambridge.

Millennium Ecosystem Assessment (2005) Living beyond our means: natural assets and human well-being. Island Press, Washington DC.

Mori AS, Furukawa T, Sasaki T (2013) Response diversity determines the resilience of ecosystems to environmental change. Biol Rev 88:349-364. doi:10.1111/brv.12004

Muller R, Bornstein C (2010) Maintaining the diversity of California's municipal forests. J Arboric $36: 18-27$.

Nepf HM (2012) Hydrodynamics of vegetated channels. J Hydraul Res 50:262-279. doi:10.1080/ 00221686.2012 .696559

Nowak DJ, Hoehn RE III, Bodine AR et al (2013) Assessing urban forest effects and values: Toronto's urban forest. U.S. Department of Agriculture, Forest Service, Northern Research Station, Newtown Square

Perrings C (1995) Biodiversity conservation as insurance. In: Swanson TM (ed) The economics and ecology of biodiversity decline: the forces driving global change. Cambridge University Press, Cambridge, pp 69-78

Renaud FG, Sudmeier-Rieux K, Estrella M, Nehren U (eds) (2016) Ecosystem-based disaster risk reduction and adaptation in practice. Springer, Cham

Roy S, Byrne J, Pickering C (2012) A systematic quantitative review of urban tree benefits, costs, and assessment methods across cities in different climatic zones. Urban For Urban Green 11:351-363. doi:10.1016/j.ufug.2012.06.006 
Tengö M, Brondizio ES, Elmqvist T et al (2014) Connecting diverse knowledge systems for enhanced ecosystem governance: the multiple evidence base approach. Ambio. doi:10.1007/ s13280-014-0501-3

The Royal Society (2014) Resilience to extreme weather. The Royal Society Science Policy Centre Report 02/14. The Royal Society, London

Walters C (1986) Adaptive management of renewable resources. McGraw Hill, New York

Webb C, Bodin Ö (2008) A network perspective on modularity and control of flow in robust systems. In: Norberg J, Cumming GS (eds) Complex theory a sustain future. Columbia University Press, New York, pp 85-118

Open Access This chapter is licensed under the terms of the Creative Commons Attribution 4.0 International License (http://creativecommons.org/licenses/by/4.0/), which permits use, sharing, adaptation, distribution and reproduction in any medium or format, as long as you give appropriate credit to the original author(s) and the source, provide a link to the Creative Commons license and indicate if changes were made.

The images or other third party material in this chapter are included in the chapter's Creative Commons license, unless indicated otherwise in a credit line to the material. If material is not included in the chapter's Creative Commons license and your intended use is not permitted by statutory regulation or exceeds the permitted use, you will need to obtain permission directly from the copyright holder. 